\title{
APPLICATION OF DIFFERENTIAL TRANSFORMATION METHOD FOR SOLVING HIV MODEL WITH ANTI-VIRAL TREATMENT
}

\section{Aplikasi Metode Tranformasi Diferensial Dalam Penyelesaian Model HIV Dengan Antiviral}

\author{
Esther Y. Bunga ${ }^{1}$, Meksianis Z. Ndii ${ }^{2 *}$ \\ 1,2 Program Studi Matematika, Fakultas Sains dan Teknik. Universitas Nusa Cendana \\ Jln. Adisucpto Kampus Baru Penfui, Kupang-Nusa Tenggara Timur, Indonesia \\ e-mail:1 estherbunga8@gmail.com ; ${ }^{2 *}$ meksianis.ndii@staf.undana.ac.id \\ Corresponding author*
}

\begin{abstract}
Mathematical models have been widely used to understand complex phenomena. Generally, the model is in the form of system of differential equations. However, when the model becomes complex, analytical solutions are not easily used and hence a numerical approach has been used. A number of numerical schemes such as Euler, Runge-Kutta, and Finite Difference Scheme are generally used. There are also alternative numerical methods that can be used to solve system of differential equations such as the nonstandard finite difference scheme (NSFDS), the Adomian decomposition method (ADM), Variation iteration method (VIM), and the differential transformation method (DTM). In this paper, we apply the differential transformation method (DTM) to solve system of differential equations. The DTM is semianalytical numerical technique to solve the system of differential equations and provides an iterative procedure to obtain the power series of the solution in terms of initial value parameters. In this paper, we present a mathematical model of HIV with antiviral treatment and construct a numerical scheme based on the differential transformation method (DTM) for solving the model. The results are compared to that of Runge-Kutta method. We find a good agreement of the DTM and the Runge-Kutta method for smaller time step but it fails in the large time step.
\end{abstract}

Keywords: DTM, Numerical methods, HIV, Model 


\section{INTRODUCTION}

Mathematical models have been widely used to understand complex phenomena and have been applied in many fields such as economics, epidemiology, biology, and social [1]-[4]. Many mathematical models have been formulated to understand complex phenomena such as disease transmission dynamics or rumor spread [4]-[8]. These models are in the form of system of differential equations and have been solved using the available software.

Biological problems are often complex and require a lot of resources to be investigated and understood clearly. Human Immunodeficiency Virus (HIV) is a major problem in the world [9] and thus its dynamics needs to be understood clearly. A mathematical model can be formulated to gain nonintuitive insights of the HIV transmission dynamics. Many mathematical models for HIV/AIDS transmission dynamics have been formulated and their corresponding numerical solutions have been presented [10][13]. They applied the nonstandard finite difference scheme and the differential transformation method for solving HIV mathematical models. Generally, they found that the solutions generated by these numerical schemes are in agreement with that use the traditional method such as Euler and Runge-Kutta.

In this paper, we implement the differential transformation method for solving HIV model with antiviral treatment. Mathematical models of HIV with anti viral treatment have also been developed [9], [14]-[16]. This paper extends the mathematical model by Priti [15] by including the logistic growth of T cells that are produced by proliferation of existing $\mathrm{T}$ cells.

A mathematical model is often complex since it includes many variables and parameters. Although several analytical analyses such as steady states can be derived, in general, the analytical solution of the models is not easily derived. Thus, a numerical approach is implemented. One of the numerical approaches to be used is the Differential Transformation Method (DTM). This method allows us to write a semianalytical solution of the model which depends on the Taylor series [17]-[21]. The DTM has been successfully applied to solve various mathematical models including disease transmission models [18], [22]. Arenas et al. [17] used the differential transformation method for solving non autonomous system of differential equations. They found that the DTM is easy to implement, accurate, and satisfy the properties of its corresponding continuous model. Research by Jodar et al. also showed that the DTM is in good agreement with the Runge-Kutta method when it is applied to linear and non-linear stiff systems of differential equations. Allahviranloo et al. (2009) implement the DTM to solve fuzzy differential equations and found the identical solution between the DTM and differential inculsion. The DTM can be applied to solve the traveling wave solution [24].

Although the DTM has been applied to solve many mathematical models and shows to be accurate, several research shows that the DTM may fail in generating solution. Ndii et al. [20] compared the performance of the DTM and the nonstandard finite difference scheme and showed that the DTM may fail in generating the solution of system of differential equations. Ghafoori et al., (2011) compared the performance of the DTM and variation iteration method (VIM) and the homotopy perturbation method (HPM) and found that the DTM is more accurate than the other two methods. Furthermore, the DTM performance is similar to that of Adomian decomposition method (ADM). In this paper, we employ the DTM to solve the HIV model with antiviral treatment. We compare the results to that generated by RungeKutta method. The focus of this paper is the construction of the DTM method for solving the formulated mathematical model. We examine the convergence of the method by using different time step. The discussion of the results is presented.

The remainder of the paper is organised as follows. Section 2 presents methods consisting of formulation of mathematical model of HIV with antiviral treatment and the differential transformation method (DTM). Results and discussions are then presented. Finally, the conclusions are presented.

\section{RESEARCH METHODS}

\subsection{Formulation of Mathematical Model}

We implement the differential transformation method to solve the HIV model in the form of system of differential equations. A mathematical model for HIV with anti-viral treatment is proposed. The model is compartment-based model in the form of system of differential equations where the population is divided into different groups depending on their status. 
We modified the model of Priti [15] by including the logistic growth of T cells as given in [16]. Let $x(t)$ be the uninfected $\mathrm{CD}^{+} \mathrm{T}$ cell population, $y_{i}(t)$ be the infected $\mathrm{CD} 4^{+} \mathrm{T}$ cell population, $y_{l}(t)$ be latently infected $\mathrm{CD} 4^{+} \mathrm{T}$ cell population and $z(t)$ be the CTL responses. We assume that the the new $\mathrm{T}$ cells are created by the proliferation of existing T cells, which is governed by a logistic function as given in [16]. Therefore, the growth of $\mathrm{T}$ cell is determined by natural growth $\lambda$ and that created by the proliferation of existing $\mathrm{T}$ cells $a x\left(1-\frac{x}{x_{\max }}\right)$. The cytotoxic $\mathrm{T}$ lymphocyte (CTL) responses at a rate $s$ where the response depends on the population of infected $\mathrm{T}$ cell. This response will kill the infected $\mathrm{T}$ cell at a rate $\beta_{2}$. Some $\mathrm{CD} 4^{+} \mathrm{T}$ cells remain in the latent class but they are activated and move to the infected class at a rate $\delta$. The RTI reduces the infection rate by $\left(1-\eta_{1} u_{1}\right)$ where $\eta_{1}$ is drug efficacy and $u_{1}$ is the control input doses of the drug RTI [15]. The detail of the explanation of the model is given in [15].

The model is governed by the following system of differential equations.

$$
\begin{aligned}
\frac{d x}{d t}= & \lambda-d x+a x\left(1-\frac{x}{x_{\max }}\right)- \\
& \left(1-\eta_{1} u_{1}\right) \beta_{1} x y_{i}+\eta_{2} u_{2} x, \\
\frac{d y_{i}}{d t}= & \left(1-\eta_{1} u_{1}\right) \beta_{1} x y_{i}-d_{2} y_{i} \\
& -\beta_{2} y_{i} z+\delta y_{l}, \\
\frac{d y_{l}}{d t}= & v y_{i}-d_{3} y_{l}-\delta y_{l}, \\
\frac{d z}{d t}= & s y_{i}-d_{4} z+\eta_{3} u_{2} z .
\end{aligned}
$$

Table 1. Parameter descriptions and values. The parameter values is given in [15], [16]

\begin{tabular}{cll}
\hline \multicolumn{1}{c}{ Description } & \multicolumn{1}{c}{ Values } \\
\hline$x_{\max }$ & Proliferation rate & 0.5 \\
\hline$\lambda$ & Maximal population level of CD4+T cells & 1200 \\
\hline$d$ & Source term for uninfected CD4 ${ }^{+}$T cells & 10 \\
\hline$d_{2}$ & Death rate of uninfected CD4 ${ }^{+}$cells & 0.03 \\
\hline$d_{3}$ & Death rate of infected CD4 $\$^{+}$T cell population & 0.3 \\
\hline$d_{4}$ & Natural death rate of latently infected T cells & 0.03 \\
\hline$\eta_{1}$ & Natural death rate of CTL responses & 0.2 \\
\hline$\eta_{2}$ & Drug efficacy & 0.9 \\
\hline$\eta_{3}$ & Drug efficacy for IL-2 for uninfected CD4+T cells & 0.2 \\
\hline$u_{1}$ & Drug efficacy for IL-2 for CTL responses & 0.9 \\
\hline$\beta_{1}$ & Control input doses of the drug RTI & 0.5 \\
\hline$\beta_{2}$ & Infection rate of uninfected cells & $6 \times 10^{-4}$ \\
\hline$\delta$ & Death of infected T cells due to CTL responses & 0.001 \\
\hline$v$ & Progression from latent to infected & 0.1 \\
\hline$s$ & Rate of infected cells undergone latent stage & 0.5 \\
\hline & CTL response rate & 0.2 \\
\hline
\end{tabular}

\subsection{The Differential Transformation Method (DTM)}

The differential transformation method is a semi-analytic numerical technique which depends on the Taylor series. The method provides an iterative procedure to obtain the power series of the solution in terms of initial value parameters. In general, the procedure of the method is follows. First, the original function is transformed using the definition of the DTM, and then the solution of the model is obtained by iterative process using the Taylor series.

In this part, we develop a numerical scheme based on the concept of the Differential Transformation Method (DTM). The definition and the procedure of obtaining the solutions of the model are presented. 
Definition 2.2.1. [16], [20], [25] Let $f(t)$ be analytic in a domain $D$ and let $t=t_{0}$ represent any point in $D$ The Differential Transformation Method (DTM) for $\mathrm{k}^{\text {th }}$ derivative of function $f(t)$ is defined as

$$
F(k)=\frac{1}{k !}\left[\frac{d^{k} f(t)}{d t^{k}}\right]_{\left(t=t_{0}\right)} \text { for } t \in D,
$$

where $f(t)$ is the original function and $F(k)$ is the transformed function.

Definition 2.2.2. [16], [20], [25] The inverse of the transformed function is defined as,

$$
f(t)=\sum_{k=0}^{\infty} F(k)\left(t-t_{0}\right)^{k}, \text { for } t \in D
$$

From Equations (2) and (3), we obtain

$$
f(t)=\sum_{k=0}^{\infty} \frac{\left(t-t_{0}\right)^{k}}{k !}\left[\frac{d^{k} f(t)}{d t^{k}}\right]_{t=t_{0}}, \quad t \in D .
$$

Equation 4 implies that the concept of differential transformation method is derived from Taylor series. We can use the Definition 2.2.1. and 2.2.2. to derive the transformed functions given in Table 2. In real application, we only use finite series for $f(t)$ as

$$
f(t)=\sum_{k=0}^{n} F(k)\left(t-t_{0}\right)^{k} .
$$

Using the above definition, we can derive the transformed function for functions. The results are given in Table 2, and details of the proofs of the transformed function in Table 2 are given in [20].

Table 2. Operation of differential transform

\begin{tabular}{cl}
\hline Original function & Transformed function \\
\hline $\mathrm{f}(\mathrm{t})=\mathrm{u}(\mathrm{t})+\mathrm{v}(\mathrm{t})$ & $\mathrm{F}(\mathrm{k})=\mathrm{U}(\mathrm{k})+\mathrm{V}(\mathrm{k})$ \\
\hline $\mathrm{f}(\mathrm{t})=\mathrm{au}(\mathrm{t})$ & $\mathrm{F}(\mathrm{k})=\mathrm{aU}(\mathrm{k})$ \\
\hline$f(t)=\frac{d u(t)}{d t}$ & $\mathrm{~F}(\mathrm{k})=(\mathrm{k}+1) \mathrm{F}(\mathrm{k}+1)$ \\
\hline $\mathrm{f}(\mathrm{t})=\mathrm{u}(\mathrm{t}) \mathrm{v}(\mathrm{t})$ & $F(K)=\sum_{l=0}^{k} V(l) U(k-1)$ \\
\hline
\end{tabular}

The procedure for deriving the solutions of system of differential equations using the DTM is the following. Let $\left[\begin{array}{ll}0 & \mathrm{~T}\end{array}\right]$ be the time interval of interest. We divide the time of interests into $M$ subinterval $\left[\begin{array}{ll}t_{m-1} & t_{m}\end{array}\right], m=1,2, \ldots M$ of equal step size. We then find the solution of each time step using the concept of differential transformation method. The process of obtaining the solutions is the following. First, we obtain the solution of the first interval $\left[\begin{array}{ll}0 & t_{1}\end{array}\right]$ using

$$
f_{1}(t)=\sum_{k=0}^{N} f_{1}(k) t^{k}, t \in\left[0, t_{1}\right]
$$

In the next time step, we use the value at $\$ \mathrm{t}=\mathrm{t} \_1 \$$ as initial condition. In general, the value at the end time of the previous time step is used as an initial condition for the next time step. This is written as

$$
f_{m}\left(t_{m}-1\right)=f_{m-1}\left(t_{m}-1\right)
$$

and the solution of each time step is approximated using 


$$
f_{m}(t)=\sum_{k=0}^{n} F_{m}(k)\left(t-t_{m-1}\right)^{k}, t \in\left[t_{m-1}, t_{m}\right] .
$$

Let $\mathrm{m}=\mathrm{M}$ the multi-step DTM gives the following solution

$$
f(t)=\left\{\begin{array}{cl}
\sum_{k=0}^{n} F_{1}(k) t^{k}, & t \in\left[0, t_{1}\right] \\
\sum_{k=0}^{N} F_{2}(k)\left(t-t_{1}\right)^{k}, & t \in\left[t_{1}, t_{2}\right] \\
\vdots & \\
\sum_{k=0}^{N} F_{m}(k)\left(t-t_{m-1}\right)^{k}, & t \in\left[t_{m-1}, t_{m}\right]
\end{array}\right.
$$

We then obtain the numerical solutions of the model.

We illustrate the use of the operation of differential transform.

$$
\frac{d x}{d t}=2 x y \text {. }
$$

The transformation of the above equation is

$$
(k+1) X(k+1)=2 \sum_{l=0}^{k} Y(l) X(k-l) .
$$

The results and discussion are presented in the next section.

\section{RESULTS AND DISCUSSION}

In this section, we present the results of the transformation of the Model 1 using the concept of the differential transformation method and the solutions of the model using the DTM. The operations of differential transform given in Table 2 are used. The transformed model is the following:

$$
\begin{aligned}
X(K+1)= & \frac{1}{k+1}(\lambda-d X(K)+a X(K) \\
& -\frac{a}{x_{\max }} \sum_{l=0}^{K} X(l) X(K-l)- \\
& \left(1-\eta_{1} u_{1}\right) \beta_{1} \sum_{l=0}^{K} X(l) Y_{i}(K-l) \\
& \left.+\eta_{2} u_{2} X(K)\right), \\
Y_{i}(K+1)= & \frac{1}{K+1}\left(\left(1-\eta_{1} u_{1}\right) \beta_{1} \sum_{l=0}^{K} X(l) y_{i}(K-l)\right. \\
& -d_{2} Y_{i}(K)-\beta_{2} \sum_{l=0}^{K} Y_{i}(l) Z(K-l) \\
& \left.+\delta Y_{l}(K)\right), \\
Y_{l}(K+1)= & \frac{1}{K+1}\left(v Y_{i}(K)-\left(d_{3}+\delta\right) Y_{l}(K)\right. \\
Z(K+1)= & \frac{1}{K+1}\left(s Y_{i}(K)-d_{4} Z(K)+\eta_{3} u_{2} Z(K) .(9)\right.
\end{aligned}
$$

The invers of this function is the solution of the model above. Let divide $t$ into $t_{1}, t_{2}, t_{3}, \ldots, t_{n}$ 


$$
\begin{aligned}
& x(t)= \begin{cases}\sum_{K=0}^{N} X(K)\left(t-t_{0}\right)^{K}, & t \in\left[\begin{array}{ll}
t_{0} & t_{1}
\end{array}\right] \\
\sum_{K=0}^{N} X(K)\left(t-t_{1}\right)^{K}, & t \in\left[\begin{array}{ll}
t_{1} & t_{2}
\end{array}\right] \\
\sum_{K=0}^{N} X(K)\left(t-t_{2}\right)^{K}, & t \in\left[\begin{array}{ll}
t_{2} & t_{3}
\end{array}\right] \\
\vdots & \\
\sum_{K=0}^{N} X(K)\left(t-t_{m-1}\right)^{K}, & t \in\left[\begin{array}{ll}
t_{m-1} & t_{m}
\end{array}\right]\end{cases} \\
& y_{i}(t)= \begin{cases}\sum_{K=0}^{N} Y_{i}(K)\left(t-t_{0}\right)^{K}, & t \in\left[\begin{array}{ll}
t_{0} & t_{1}
\end{array}\right] \\
\sum_{K=0}^{N} Y_{i}(K)\left(t-t_{1}\right)^{K}, & t \in\left[\begin{array}{ll}
t_{1} & t_{2}
\end{array}\right] \\
\sum_{K=0}^{N} Y_{i}(K)\left(t-t_{2}\right)^{K}, & t \in\left[\begin{array}{ll}
t_{2} & t_{3}
\end{array}\right] \\
\vdots & \\
\sum_{K=0}^{N} Y_{i}(K)\left(t-t_{m-1}\right)^{K}, & t \in\left[\begin{array}{ll}
t_{m-1} & t_{m}
\end{array}\right]\end{cases} \\
& y_{l}(t)= \begin{cases}\sum_{K=0}^{N} Y_{l}(K)\left(t-t_{0}\right)^{K}, & t \in\left[\begin{array}{ll}
t_{0} & t_{1}
\end{array}\right] \\
\sum_{K=0}^{N} Y_{l}(K)\left(t-t_{1}\right)^{K}, & t \in\left[\begin{array}{ll}
t_{1} & t_{2}
\end{array}\right] \\
\sum_{K=0}^{N} Y_{l}(K)\left(t-t_{2}\right)^{K}, & t \in\left[\begin{array}{ll}
t_{2} & t_{3}
\end{array}\right] \\
\vdots & \\
\sum_{K=0}^{N} Y_{l}(K)\left(t-t_{m-1}\right)^{K}, & t \in\left[\begin{array}{ll}
t_{m-1} & t_{m}
\end{array}\right]\end{cases} \\
& z(t)= \begin{cases}\sum_{K=0}^{N} Z(K)\left(t-t_{0}\right)^{K}, & t \in\left[\begin{array}{ll}
t_{0} & t_{1}
\end{array}\right] \\
\sum_{K=0}^{N} Z(K)\left(t-t_{1}\right)^{K}, & t \in\left[\begin{array}{ll}
t_{1} & t_{2}
\end{array}\right] \\
\sum_{K=0}^{N} Z(K)\left(t-t_{2}\right)^{K}, & t \in\left[\begin{array}{ll}
t_{2} & t_{3}
\end{array}\right] \\
\vdots & \\
\sum_{K=0}^{N} Z(K)\left(t-t_{m-1}\right)^{K}, & t \in\left[\begin{array}{ll}
t_{m-1} & t_{m}
\end{array}\right]\end{cases}
\end{aligned}
$$

In this section, we present a numerical experiments of the DTM for the HIV model. The parameter values are given in Table 1. Here we compare the results using DTM and the Runge Kutta. The results are given 
in Figure 1. Numerical comparison between Runge-Kutta and Differential Transformation Method for $\mathrm{h}=0.001$ and Table 3 .

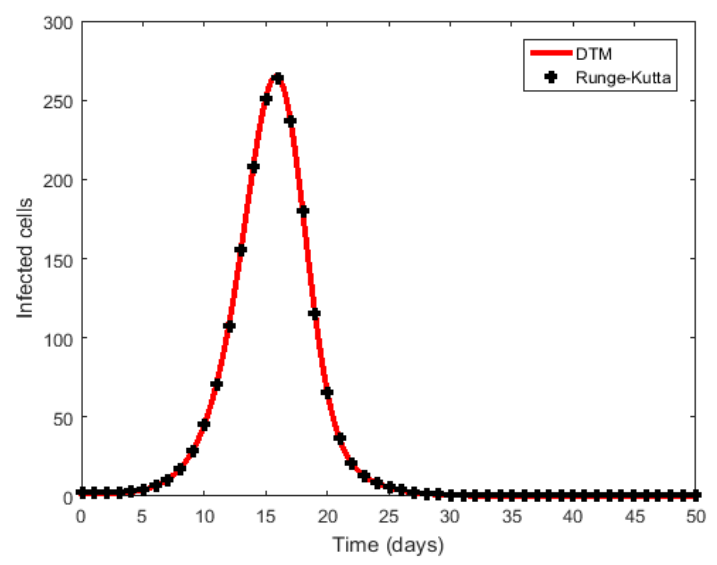

Figure 1. Numerical comparison between Runge-Kutta and Differential Transformation Method for $h=0.001$

Figure 1 shows that the DTM is in agreement with the Runge-Kutta method. The result differences between the DTM and Runge-Kutta are given in Table 3. The model is for the time step of 0.01. However, when we increase the time step $h$ the solution cannot be generated as given in Figure 2.

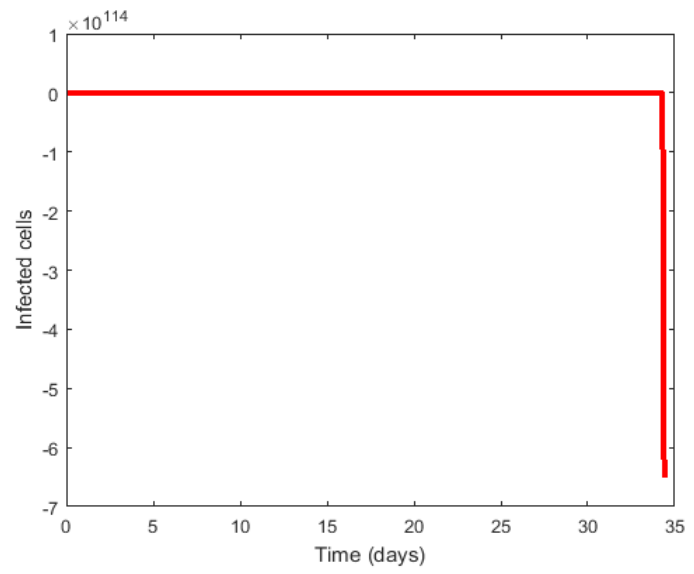

Figure 2. The solution using the Differential Transformation Method for $h=0.1$.

Table 3. The error of the numerical results of the model using the differential transformation method and Runge-Kutta method. The time step is 0.01 and error tolerance for Runge-Kutta is $10^{-6}$

\begin{tabular}{ll}
\hline \multicolumn{1}{c}{ (days) } & Differences \\
\hline 5 & 0.000115545 \\
\hline 10 & 0.001754874 \\
\hline 15 & 0.005111424 \\
\hline 20 & 0.002726564 \\
\hline 25 & 0.000149172 \\
\hline 30 & $1.82729 \times 10^{-5}$ \\
\hline 35 & $2.73116 \times 10^{-6}$ \\
\hline 40 & $6.68361 \times 10^{-7}$ \\
\hline 45 & $6.79724 \times 10^{-8}$ \\
\hline 50 & $1.3401 \times 10^{-9}$ \\
\hline
\end{tabular}

This paper aims to construct the DTM to solve anti-viral treatment. This shows that the DTM can generate the solutions of the model. However, it shows that the DTM cannot generate the solution if the time step $\mathrm{h}$ is not appropriate. We found that although the time step is 0.1 , the DTM cannot generate the solution. The same results are found by Ndii et al. [25], and Odibat (2008). The DTM has been applied to many mathematical models and found a good agreement between the DTM and the traditional methods 
such as Runge-Kutta and Euler methods. However, in this paper, our results suggest that the DTM cannot generate the solution of the model if the time step is high.

The results imply that the DTM may not appropriate for the use in solving system of differential equations when the traditional methods fail in generating solution. Given that the traditional numerical schemes such as Runge-Kutta, Euler fail in generating the solution of differential equations, an alternative numerical schemes are required. A number of numerical schemes has been proposed such as the nonstandard finite difference scheme (NSFDS), Adomian Decomposition method (ADM), Variation iteration method (VIM), homotopy perturbation method (HPM) [26]-[31]. A little research has been done to compare the performance between the NSFDS and the DTM. Ndii et al. [25] compared the performance between these methods and showed that the similar performance of the NSFDS and DTM in small time step. When the time step is larger, the DTM fails in generating the solution. The performance of the DTM is similar to Adomian decomposition method (ADM) [27] and is more accurate than the Variational iteration method (VIM) and Homotopy perturbation method (HPM) [26]. Furthermore, the DTM can be modified to enhance its performance to generate the solutions of the system of differential equations.

The results suggest that the use of the numerical schemes depends on the problems to be solved. The DTM performs better than the VIM and HPM but is not better than the ADM and the NSFDS. Therefore, the use of the DTM can be applied for the smaller time step.

\section{CONCLUSIONS}

Research showed that the DTM is only effective for a small time step. When the time step is higher, the DTM fails in generating the solutions of the model. Some modifications may be required to enhance the performance of the method but it is not the focus of the paper.

\section{ACKNOWLEDGEMENT}

MZN acknowledges funding from Ministry of Research and Technology through Penelitian Dasar Unggulan Perguruan Tinggi (PDUPT) scheme (2019-2020).

\section{REFERENCES}

[1] T. Bakary, S. Boureima, and T. Sado, "A mathematical model of malaria transmission in a periodic environment," Journal of Biological Dynamics, vol. 12, no. 1, pp. 400-432, Jan. 2018, doi: 10.1080/17513758.2018.1468935.

[2] M. Z. Ndii, E. Carnia, and A. K. Supriatna, "Mathematical Models for the Spread of Rumors: A Review," in Issues and Trends in Interdisciplinary Behavior and Social Science, F. L. Gaol, F. Hutagalung, and F. P. Chew, Eds. CRC Press, 2018, pp. 266-290.

[3] M. Z. Ndii, Z. Amarti, E. D. Wiraningsih, and A. K. Supriatna, "Rabies epidemic model with uncertainty in parameters: crisp and fuzzy approaches," IOP Conference Series: Materials Science and Engineering, vol. 332, no. 1, p. 012031, 2018.

[4] N. Anggriani, H. Tasman, M. Z. Ndii, A. K. Supriatna, E. Soewono, and E. Siregar, "The effect of reinfection with the same serotype on dengue transmission dynamics," Applied Mathematics and Computation, vol. 349, pp. 62-80, 2019, doi: https://doi.org/10.1016/j.amc.2018.12.022.

[5] J. Yang, C. Modnak, and J. Wang, "Dynamical analysis and optimal control simulation for an age-structured cholera transmission model," Journal of the Franklin Institute, vol. 356, no. 15, pp. 8438-8467, 2019, doi: https://doi.org/10.1016/j.jfranklin.2019.08.016.

[6] M. Z. Ndii, F. R. Berkanis, D. Tambaru, M. Lobo, Ariyanto, and B. S. Djahi, "Optimal control strategy for the effects of hard water consumption on kidney-related diseases," BMC Research Notes, vol. 13, no. 1, p. 201, Apr. 2020, doi: 10.1186/s13104-020-05043-z.

[7] D. Tambaru, B. S. Djahi, and M. Z. Ndii, "The effects of hard water consumption on kidney function: Insights from mathematical modelling," AIP Conference Proceedings, vol. 1937, no. 1, p. 020020, 2018, doi: 10.1063/1.5026092.

[8] R. U. Hurint, M. Z. Ndii, and M. Lobo, “Analisis sensitivitas dari model epidemi SEIR," Natural Science: Journal of Science and Technology, vol. 6, no. 1, pp. 22-28, 2017. 
[9] M. A. Nowak and C. R. M. Bangham, "Population Dynamics of Immune Responses to Persistent Viruses," Science, vol. 272, no. 5258, pp. 74-79, 1996, doi: 10.1126/science.272.5258.74.

[10] S. Zibaei and M. Namjoo, "A nonstandard finite difference scheme for solving fractional-order model of HIV-1 infection of CD $4^{\wedge}\{+\}$ t-cells," Iranian Journal of Mathematical Chemistry, vol. 6, no. 2, pp. 169-184, 2015, doi: 10.22052/ijmc.2015.10843.

[11] D. Baleanu, H. Mohammadi, and S. Rezapour, "Analysis of the model of HIV -1 infection of CD4+\$CD4^\{+\}\$ T-cell with a new approach of fractional derivative," Advances in Difference Equations, vol. 2020, no. 1, p. 71, Feb. 2020, doi: 10.1186/s13662-020-02544-w.

[12] M. Y. Ongun and İ. Turhan, "A Numerical Comparison for a Discrete HIV Infection of CD4+ T-Cell Model Derived from Nonstandard Numerical Scheme," Journal of Applied Mathematics, vol. 2013, no. 375094, pp. 19, 2013, doi: 10.1155/2013/375094.

[13] M. Y. Ongun, "The Laplace Adomian Decomposition Method for solving a model for HIV infection of CD4+T cells," Mathematical and Computer Modelling, vol. 53, no. 5, pp. 597-603, Mar. 2011, doi: 10.1016/j.mcm.2010.09.009.

[14] A. L. Hill, D. I. S. Rosenbloom, M. A. Nowak, and R. F. Siliciano, "Insight into treatment of HIV infection from viral dynamics models," Immunological Reviews, vol. 285, no. 1, pp. 9-25, 2018, doi: 10.1111/imr.12698.

[15] P. K. Roy, Mathematical Models for Therapeutic Approaches to Control HIV Disease Transmission. Springer Singapore, 2015.

[16] X. Zhou, X. Song, and X. Shi, "A differential equation model of HIV infection of CD4+ T-cells with cure rate," Journal of Mathematical Analysis and Applications, vol. 342, no. 2, pp. 1342-1355, Jun. 2008, doi: 10.1016/j.jmaa.2008.01.008.

[17] A. J. Arenas, G. González-Parra, and B. M. Chen-Charpentier, "Dynamical analysis of the transmission of seasonal diseases using the differential transformation method," Mathematical and Computer Modelling, vol. 50, no. 5, pp. 765-776, Sep. 2009, doi: 10.1016/j.mcm.2009.05.005.

[18] L. Jodar, R. J. Villanueva, A. J. Arenas, and G. C. Gonzalez, "Nonstandard numerical methods for a mathematical model for influenza disease," Mathematics and Computers in Simulation, vol. 79, no. 3, pp. 622633, 2008, doi: https://doi.org/10.1016/j.matcom.2008.04.008.

[19] M. Z. Ndii, N. Anggriani, and A. K. Supriatna, "Application of differential transformation method for solving dengue transmission mathematical model," Symposium on Biomathematics. AIP Conference Proceeding, 2018.

[20] Z. M. Odibat, "Differential transform method for solving Volterra integral equation with separable kernels," Mathematical and Computer Modelling, vol. 48, no. 7, pp. 1144-1149, Oct. 2008, doi: 10.1016/j.mcm.2007.12.022.

[21] E. Bunga, J. Pahnael, M. Lobo, and M. Z. Ndii, "Konstruksi Metode Transformasi Diferensial Multi-Step (Multi-Step Differential Transform Method) untuk Model SEIRS Autonomous dan Nonautonomous," Matematika Integratif, vol. 16, no. 1, pp. 53-59, 2020.

[22] B. Dhar and P. K. Gupta, "Numerical Solution of Tumor-Immune Model with Targeted Chemotherapy by Multi Step Differential Transformation Method," in Intelligent Techniques and Applications in Science and Technology, Cham, 2020, pp. 404-411.

[23] T. Allahviranloo, N. A. Kiani, and N. Motamedi, "Solving fuzzy differential equations by differential transformation method," Information Sciences, vol. 179, no. 7, pp. 956-966, Mar. 2009, doi: 10.1016/j.ins.2008.11.016.

[24] H. F. Ganji, M. Jouya, S. A. Mirhosseini-Amiri, and D. D. Ganji, "Traveling wave solution by differential transformation method and reduced differential transformation method," Alexandria Engineering Journal, vol. 55, no. 3, pp. 2985-2994, Sep. 2016, doi: 10.1016/j.aej.2016.04.012.

[25] M. Z. Ndii, N. Anggriani, and A. K. Supriatna, "Comparison of the differential transformation method and non standard finite difference scheme for solving plant disease mathematical model," Communication in Biomathematical sciences, vol. 1, no. 2, pp. 110-121, 2018.

[26] S. Ghafoori, M. Motevalli, M. G. Nejad, F. Shakeri, D. D. Ganji, and M. Jalaal, "Efficiency of differential transformation method for nonlinear oscillation: Comparison with HPM and VIM," Current Applied Physics, vol. 11, no. 4, pp. 965-971, Jul. 2011, doi: 10.1016/j.cap.2010.12.018.

[27] I. H. Abdel-Halim Hassan, "Comparison differential transformation technique with Adomian decomposition method for linear and nonlinear initial value problems," Chaos, Solitons \& Fractals, vol. 36, no. 1, pp. 53-65, Apr. 2008, doi: 10.1016/j.chaos.2006.06.040.

[28] R. E. Mickens, Nonstandard finite difference models of differential equations. world scientific, 1994.

[29] R. E. Mickens, "Calculation of denominator functions for nonstandard finite difference schemes for differential equations satisfying a positivity condition," Numerical Methods for Partial Differential Equations, vol. 23, no. 3, pp. 672-691, 2007.

[30] R. E. Mickens, "Nonstandard Finite Difference Methods," in Advances in the Applications of Nonstandard Finite Difference Schemes, World Scientific, 2012, pp. 1-9.

[31] A. Suryanto, W. M. Kusumawinahyu, I. Darti, and I. Yanti, "Dynamically consistent discrete epidemic model with modified saturated incidence rate," Computational and Applied Mathematics, vol. 32, pp. 373-383, 2013, doi: https://doi.org/10.1007/s40314-013-0026-6. 
